\title{
An empirical investigation of interstate AFDC benefit competition*
}

\author{
PATRICIA K. SMITH \\ Department of Social Sciences, University of Michigan - Dearborn, Dearborn, MI 48128-1491
}

Submitted 14 June 1989; accepted 31 August 1989.

\begin{abstract}
Claims that states which offer generous welfare benefits attract the poor and that some states pay low benefits intending to drive the poor away are neither uncommon nor entirely unfounded. This paper employs a two player (state) generalized game to model states' choice of a benefit level in the Aid to Families with Dependent Children (AFDC) program. Migration by the poor in response to interstate differentials in earnings and welfare opportunities, and the subsequent changes in AFDC caseloads, drive this game.

Estimation of the model (using 1979 data) suggests that states within approximately 750 miles of each other do engage in a benefit-setting game. The rival's initial number of poor and preference for non-AFDC consumption appear to be the more influential rival characteristics.

These findings, while derived from a different methodological approach, are consistent with previous studies which indicate that welfare recipients tend to move toward higher benefit states. Such migration may impede the efficient spatial allocation of labor. The results also indicate that states will tend to offer lower benefits given recipient migration than would be the case otherwise. State jurisdiction over benefits consequently leads to underprovision of AFDC. Federalization of the AFDC program would improve efficiency in terms of the spatial allocation of labor and the provision of AFDC.
\end{abstract}

\section{Introduction}

Observers of welfare programs have frequently cautioned that generous benefits will attract additional recipients. A number of studies, for example Gramlich and Laren (1984) and Blank (1988) show that when the poor move, they are more likely to move to locations offering relatively higher benefits. Such migration could significantly affect states' welfare caseloads and thus total program expenditures. Accordingly one might expect a state to anticipate the migration impact of its benefit choice.

Few studies formally model the potential feedback from recipient migration to average benefit levels. ${ }^{1}$ Smith (1988) presents a model in which two states engage in a noncooperative AFDC benefit-setting game. Each bases its decision on the impact of anticipated migration on total AFDC expenditures, taking the earned and unearned income opportunities in the rival state as given.

\footnotetext{
* Thanks to William Milberg, Herve Moulin, Stephen Sheppard and Richard Steinberg for their comments and suggestions.
} 
This paper uses 1979 data to estimate and test the game theoretic model. The pattern of benefits offered by states within at least 750 miles of each other is consistent with the model's implications. The most influential of the rival's characteristics is the number of poor: The more poor in the rival state, the lower the selected AFDC benefit level, ceteris paribus. The rival's income and taste for non-AFDC goods also exhibit significant influence.

Section 2 presents the model and its comparative static properties. Section 3 proposes one method for defining "the rival" and discusses other model specification issues. We then use Two Stage Least Squares to estimate the model. Section 4 summarizes the results and conclusions.

\section{Review of the model}

Consider two states, each of which must decide how to allocate resources between the provision of a minimum living standard (the AFDC benefit level) and the provision of all other publicly provided goods. Both the benefit level and the composite alternative can be assumed to be purely public goods without loss of generality. We assume that each voter or legislator has single-peaked preferences over the benefit level, thus we model the "state's choice" as the maximization of a single utility function, that of the median voter:

$$
\max U_{i}=U\left(C_{i}, b_{i}\right)
$$

subject to $I_{i}=C_{i}+s_{i} b_{i} T_{i}\left(P_{i}+G_{i}\left(b_{i} ; b_{j}\right)\right)$

where:

$\mathrm{P}_{\mathrm{i}}=$ initial number of poor in state $\mathrm{i}$;

$I_{i}=$ annual income of state $i$, assumed exogenous;

$\mathrm{C}_{\mathrm{i}}=$ annual consumption of all other goods in state $\mathrm{i}, \mathrm{C}_{\mathrm{i}} \geq 0$. The price of this composite public good is normalized to unity;

$b_{i}=$ average annual AFDC benefit per recipient in state $i$;

$\mathrm{T}_{\mathrm{i}}=$ the probability of unemployment (being on AFDC) in state $\mathrm{i}$;

$s_{j}=$ state $i$ 's share of the benefit ( $\$ 1$ - federal share);

$\mathrm{G}_{\mathrm{i}}=$ net migration from state $\mathrm{j}$ to state $\mathrm{i}$.

The inclusion of the net migration function $\left(\mathrm{G}_{\mathrm{i}}\right)$ reflects that the state (or its voters) anticipates changes in the caseload due to migration induced by the chosen benefit level. Specifically, the marginal cost of offering a $\$ 1$ higher benefit will not generally be $s_{i} b_{i} T_{i} P_{i}$. When recipients migrate, the marginal cost is instead $s_{i} b_{i} T_{i}\left(P_{i}+G_{i}\right)$ : There is both a dollar cost and a caseload cost associated with changes in the benefit level.

The migration function follows from each poor resident's migration deci- 
sion. Following Sjaastad's (1962) migration-as-an-investment model and assuming risk neutrality, a poor resident will move if doing so increases his or her expected income by an amount in excess of migration costs. That is:

$$
\begin{aligned}
\text { Migrate to state } j \text { if: } & \left(T_{j} b_{j}+\left(1-T_{j}\right) E_{j}-T_{i} b_{i}-\left(1-T_{i}\right) E_{i}\right) \\
-c_{i j}-M_{i}(n)>0 &
\end{aligned}
$$

Stay in state i otherwise.

Or equivalently,

$$
\text { Migrate to state } \mathrm{j} \text { if } \mathrm{M}_{\mathrm{i}}(\mathrm{n})<\tilde{\mathrm{m}}_{\mathrm{i}}
$$

where

$$
\tilde{m}_{i}=\left(T_{j} b_{j}+\left(1-T_{j}\right) E_{j}-T_{i} b_{i}-\left(1-T_{i}\right) E_{i}\right)-c d_{i j}
$$

$T_{i, j}=$ the probability of unemployment in state $i, j ;$

$E_{i, j} \quad=$ average annual earnings of a poor resident of state $i, j ;$

$\mathrm{c}=$ the cost of migration per mile;

$\mathrm{d}_{\mathrm{ij}} \quad=$ the distance between states $\mathrm{i}$ and $\mathrm{j}$, in miles; ${ }^{2}$

$\mathrm{M}_{\mathrm{i}}(\mathrm{n})=$ the psychic cost of migration of resident $\mathbf{n}$ of state $i$.

To keep the model tractable, we assume that psychic costs $\left(M_{i}(n)\right)$ are uniformly distributed over each state's poor with a maximum of $\mathrm{K}_{\mathrm{i}, \mathrm{j}}$. The probability that a randomly selected poor resident of state $i$ will migrate to state $j$ is then $\tilde{\mathrm{m}}_{\mathrm{i}} / \mathrm{K}_{\mathrm{i}}$ for $\tilde{\mathrm{m}}_{\mathrm{i}}>0$ and 0 otherwise. State $\mathrm{i}$ can expect, given its employment and demographic characteristics and those of the rival, that a particular benefit level will induce out-migration in the amount:

$$
\operatorname{Mig}(\mathrm{i} \rightarrow \mathrm{j})=\max \left\{0, \mathrm{P}_{\mathrm{i}} \tilde{\mathrm{m}}_{\mathrm{i}} / \mathrm{K}_{\mathrm{i}}\right\}
$$

and in-migration in the amount:

$$
\operatorname{Mig}(j \rightarrow \mathrm{i})=\max \left\{0, \mathrm{P}_{\mathrm{j}} \tilde{\mathrm{m}}_{\mathrm{j}} / \mathrm{K}_{\mathrm{j}}\right\}
$$

Net migration is simply:

$$
\mathrm{G}_{\mathrm{i}}\left(\mathrm{b}_{\mathrm{i}} ; \mathrm{b}_{\mathrm{j}}\right)=\operatorname{Mig}(\mathrm{j} \rightarrow \mathrm{i})-\operatorname{Mig}(\mathrm{i} \rightarrow \mathrm{j}) .
$$

$G_{i}$ is a continuous non-negative function in $b_{i}$ which can be divided into five distinct regions (Figure 1). In Region 4, state i pays a benefit so high that it attracts all of state j's poor. In Region 5, state i offers such a low benefit that all of its poor migrate to $j$. In Region $1, b_{i}$ is sufficiently low to encourage 


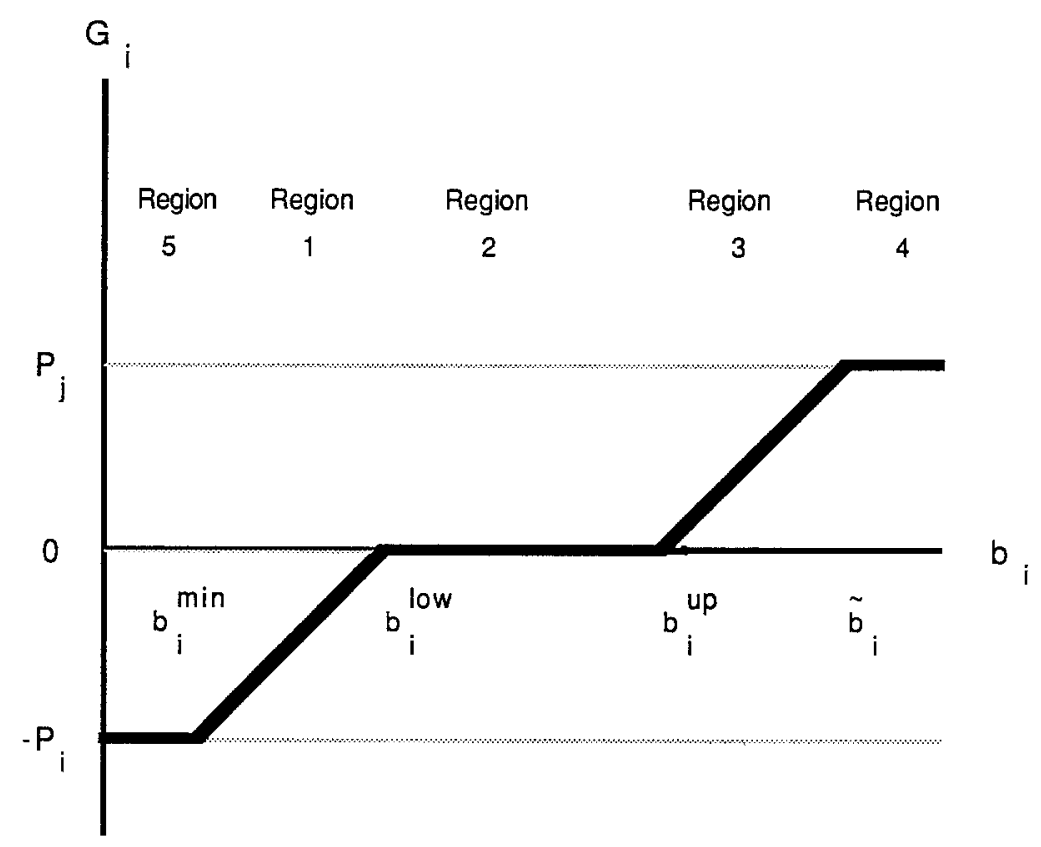

Figure 1. Net migration to state $\mathrm{i}$ as a function of its AFDC benefit.

some residents to migrate, while in Region $3 b_{i}$ is high enough to attract some of state $j$ 's poor. Finally, as long as residents face positive migration costs there is a range of benefits, $b_{i}^{\text {low }}$ to $b_{i}^{\text {up }}$, which induces no migration:

$$
\begin{aligned}
& b_{i}^{\text {low }}=\frac{\left\{\left(1-T_{j}\right) E_{j}-\left(1-T_{i}\right) E_{i}+T_{j} b_{j}\right\}-c d_{i j}}{T_{i}} \\
& b_{i}^{\text {up }}=\frac{\left\{\left(1-T_{j}\right) E_{j}-\left(1-T_{j}\right) E_{i}+T_{j} b_{j}\right\}+c d_{i j}}{T_{i}}
\end{aligned}
$$

Region 2, where the game is suspended, is $2 \mathrm{~cd}_{\mathrm{ij}} / \mathrm{T}_{\mathrm{i}}$ dollars wide. This range expands as either distance $\left(d_{i j}\right)$ or variable migration costs (c) increase. This result implies that AFDC benefit competition will take place only within limited geographic regions. States far from each other, for example Maine and Arizona, set their respective benefit levels independently of each other. Also, recipient populations which have high migration costs, such as the ill or disabled, are less likely to move in response to benefit differentials. Transfer programs targeted at these groups probably will not experience interstate benefit competition.

Suppose each state behaves as if it were maximizing a Cobb-Douglas utility function:

$$
\mathrm{U}_{\mathrm{i}}\left(\mathrm{C}_{\mathrm{i}}, \mathrm{b}_{\mathrm{i}}\right)=\mathrm{C}_{\mathrm{i}} \gamma^{\mathrm{i}} \mathrm{b}_{\mathrm{i}}^{\left(1-\gamma_{\mathrm{i}}\right)}
$$


Assuming that $U_{i}$ is monotonic, the state's choice can be reduced from a pair $\left(\mathrm{C}_{\mathrm{i}}, \mathrm{b}_{\mathrm{i}}\right)$ to simply $\mathrm{b}_{\mathrm{i}}$ :

$$
\mathrm{U}_{\mathrm{i}}\left(\mathrm{b}_{\mathrm{i}}, \mathrm{b}_{\mathrm{j}}\right)=\left(\mathrm{I}_{\mathrm{i}}-\mathrm{s}_{\mathrm{i}} \mathrm{T}_{\mathrm{i}} \mathrm{b}_{\mathrm{i}}\left(\mathrm{P}_{\mathrm{i}}+\mathrm{G}_{\mathrm{i}}\left(\mathrm{b}_{\mathrm{i}} ; \mathrm{b}_{\mathrm{j}}\right)\right)\right)^{\gamma \mathrm{i}} \mathrm{b}_{\mathrm{i}}^{\left(1-\gamma_{\mathrm{i}}\right)}
$$

Because $G_{i}$ is continuous in $b_{i}$ and $b_{j}, U_{i}$ is continuous in $b_{i}$. Furthermore, it can be shown that if the choice set is convex, $U_{i}$ is quasi-concave in $b_{i}$. If the choice set is not convex, $U_{i}$ may not be quasi-concave and equilibrium may not exist. Restricting our attention to the case of convex choice sets, the game with Cobb-Douglas utility functions satisfies established conditions for existence of an equilibrium. ${ }^{3}$

Maximizing (11) with respect to $b_{i}$ yields the following first order condition:

$$
\mathrm{s}_{\mathrm{i}} \mathrm{T}_{\mathrm{i}} \mathrm{b}_{\mathrm{i}}\left(\mathrm{P}_{\mathrm{i}}+\gamma_{\mathrm{i}} \mathrm{b}_{\mathrm{i}} \frac{\partial \mathrm{G}_{\mathrm{i}}}{\partial \mathrm{b}_{\mathrm{i}}}+\mathrm{G}_{\mathrm{i}}\right)-\left(1-\gamma_{\mathrm{i}}\right) \mathrm{I}_{\mathrm{i}}=0
$$

Solving (12) for $b_{i}$ produces state i's reaction function:

$$
b_{i}=\frac{-\left(P_{i}+G_{i}\right)+\sqrt{\left(P_{i}+G_{i}\right)^{2}-4 \gamma_{i} \frac{\partial G_{i}}{\partial b_{i}} \frac{\left(\gamma_{i}-1\right) I_{i}}{s_{i} T_{i}}}}{2 \gamma_{i} \frac{\partial G_{i}}{\partial b_{i}}}
$$

$G_{i}$ is however a function of $b_{i}$. To solve for $b_{i}$ we must substitute in the appropriate region of the migration function. State $i$ will accordingly have a reaction function comprised of three parts, each describing the utility maximizing benefit level given the migration parameters and the region. For a given $b_{j}$, state $i$ will calculate the best response in each of Regions 1, 2, and 3 and will offer the feasible best response which yields the highest utility.

The simplest case is a Region 2 equilibrium, where there is no migration. The first order condition (12) reduces to:

$$
s_{\mathrm{i}} \mathrm{T}_{\mathrm{i}} \mathrm{b}_{\mathrm{i}} \mathrm{P}_{\mathrm{i}}-\left(1-\gamma_{\mathrm{i}}\right) \mathrm{I}_{\mathrm{i}}=0 \text {. }
$$

The optimal benefit level, or best response, is $b_{i 2}=\frac{\left(1-\gamma_{i}\right) I_{i}}{s_{i} T_{i} P_{i}}$.

The comparative static properties of the equilibrium benefit can now be easily determined: 


$$
\frac{\partial \mathrm{b}_{\mathrm{i} 2}}{\partial \gamma_{\mathrm{i}}}<0, \frac{\partial \mathrm{b}_{\mathrm{i} 2}}{\partial \mathrm{I}_{\mathrm{i}}}>0, \frac{\partial \mathrm{b}_{\mathrm{i} 2}}{\partial \mathrm{s}_{\mathrm{i}}}<0, \frac{\partial \mathrm{b}_{\mathrm{i} 2}}{\partial \mathrm{P}_{\mathrm{i}}}<0, \frac{\partial \mathrm{b}_{\mathrm{i} 2}}{\partial \mathrm{T}_{\mathrm{i}}}<0
$$

The higher the Cobb-Douglas utility weight on non-AFDC consumption, the lower will be the equilibrium benefit. This suggests the intuitively obvious; states with lower preferences for poverty relief will offer lower average AFDC benefits. Second, the higher the state's income, the higher the benefit it will offer - the income effect for normal goods. Third, the lower is the state's share (the higher is the federal share), the higher will be the benefit level offered the standard price response. Fourth, the greater the state's number of poor, and thus the higher the marginal caseload price of $b_{i}$, the lower will be the equilibrium benefit. This again is a standard price response. Finally, the higher the probability of unemployment, the lower will be the benefit level because more residents will depend on AFDC; i.e., the caseload price is higher. None of the rival's characteristics influence $b_{i}$ : When there is no migration each state acts as a fully independent maximizing agent.

In Region 4, where all of state j's poor migrate to $i$, the first order condition is:

$$
\mathrm{s}_{\mathrm{i}} \mathrm{T}_{\mathrm{i}} \mathrm{b}_{\mathrm{i}}\left(\mathrm{P}_{\mathrm{i}}+\mathrm{P}_{\mathrm{j}}\right)-\left(1-\gamma_{\mathrm{i}}\right) \mathrm{I}_{\mathrm{i}}=0
$$

and the optimal benefit level is $b_{i 4}=\frac{\left(1-\gamma_{i}\right) I_{i}}{s_{i} T_{i}\left(P_{i}+P_{j}\right)}$. The same comparative static results hold as in Region 2 and in addition: $\frac{\partial \mathrm{b}_{i 4}}{\partial \mathrm{P}_{\mathbf{j}}}<0$. The more poor in the rival state (thus the greater the caseload price), the lower will be the equilibrium benefit level.

In Regions 1 and 3 migration occurs and the states play the generalized game. Consequently migration costs and the rival's characteristics influence the AFDC benefit choice. Substituting (5) into (13) produces state i's best Region 1 (out-migration) response:

$$
b_{i}=\frac{-P_{i}\left(1-\frac{1}{K_{i}}\left(\left(1-T_{j}\right) E_{j}-\left(1-T_{i}\right) E_{i}+T_{j} b_{j}\right)-c d_{i j}\right)}{2 \frac{P_{i}}{K_{i}} T_{i}\left(1+\gamma_{i}\right)}+
$$

$$
\frac{\sqrt{P_{i}^{2}\left(1-\frac{1}{K_{i}}\left(\left(1-T_{j}\right) E_{j}-\left(1-T_{i}\right) E_{i}+T_{j} b_{j}\right)-c d_{i j}\right)^{2}-4 \frac{P_{i}}{K_{i}} \frac{\left(\gamma_{i}+1\right)\left(\gamma_{i}-1\right) I_{i}}{s_{i}}}}{2 \frac{P_{i}}{K_{i}} T_{i}\left(1+\gamma_{i}\right)}
$$


Substituting (6) into (13) produces state i's best Region 3 (in-migration) response:

$$
\begin{aligned}
& b_{i}=\frac{-\left(P_{i}+\frac{P_{j}}{K_{j}}\left(\left(1-T_{i}\right) E_{i}-\left(1-T_{j}\right) E_{j}-T_{j} b_{j}\right)-c d_{i j}\right)}{2 \frac{P_{j}}{K_{j}} T_{i}\left(1+\gamma_{i}\right)}+ \\
& \sqrt{\left(P_{i}+\frac{P_{j}}{K_{j}}\left(\left(1-T_{j}\right) E_{i}-\left(1-T_{j}\right) E_{j}-T_{j} b_{j}\right)-c d_{i j}\right)^{2}-4 \frac{P_{j}}{K_{j}} \frac{\left(\gamma_{i}+1\right)\left(\gamma_{i}-1\right) I_{i}}{s_{i}}} \\
& \frac{2 \frac{P_{j}}{K_{j}} T_{i}\left(1+\gamma_{i}\right)}{s_{j}}
\end{aligned}
$$

The rival's reaction functions for Region 1 and 3 can be similarly derived and are likewise complex.

To solve for state i's equilibrium benefit level, assuming it exports recipients to state $\mathrm{j}$, substitute j's best "import" response into (15) and solve for $b_{i}$. Conversely, substituting (16) into $j$ 's best "export" response produces state $j$ 's equilibrium benefit level, given that it imports recipients. Because each state's "regional" reaction function is quite complex, these substitutions produce very lengthy and complicated expressions for which apparently no closed-form solution can be derived.

We simulate the AFDC benefit game through an iterative search routine. ${ }^{4}$ The game begins with $\mathrm{bj}=0$, to which state $\mathrm{i}$ makes the utility maximizing response. The program determines this response by calculating state i's three regional best responses to $b_{j}=0$. State $i$ plays the regional best response for which the highest utility obtains. State j's "global" best response is then calculated similarly. This process continues until the sign of the difference in consecutive $b_{i}$ 's reverses. This indicates that the search routine has past the point of intersection of the states' best response functions. The program then begins a convergence routine which locates the intersection (equilibrium) within $\$ 0.001$. The program also determines the pattern of migration and checks the convexity of state i's budget constraint at equilibrium. The exogenous values employed all lie within the range of levels observed in 1979.

Previous studies typically find that the larger a state's poor population, the lower on average are the state's welfare benefits (e.g., Orr, 1976). The model simulations also indicate an inverse relationship between the number of poor and the average benefit level. This result obtains because the greater the number of poor, the greater is the marginal cost of increasing the benefit level.

The model also implies that a state responds to the number of poor in the 
rival state. Specifically, the larger the number of poor in the rival state, the lower will be the state's own equilibrium benefit. A state recognizes that offering a benefit level which induces the in-migration of even a small fraction of the rival's poor can mean a large absolute increase in its AFDC caseload. Thus, a state sets a lower benefit than would be the case if its rival's poor population were smaller.

Simulations of the impact of changes in state income indicate that the higher the state's income, the higher on average is its AFDC benefit. This result simply reflects the income effect for normal goods and is common in the literature. The model further predicts that the higher the rival state's income, the higher will be the state's own benefit. A higher rival state income implies a higher rival state benefit. A state can then raise its own benefit without attracting as many of the rival's poor.

The simulations indicate that the current federal matching program has a positive effect on a state's choice of benefits: The higher the federal share (the lower the state's share), the higher is the state's equilibrium benefit. This implication is consistent with findings by Pogue and Sgontz (1968), Orr (1976), and Craig and Inman (1985). The model also implies that the higher the federal share paid to the rival state, the higher will be the state's own equilibrium benefit. The higher the federal share in the rival state, the higher the rival's benefit level and the smaller the expected gain from migration. Consequently the caseload price is lower and the state offers a higher benefit. Conversely, lowering either state's federal share will lower state i's benefit level. A nationwide cut in federal support will thus have not one, but two depressing effects on the benefit level in each state.

Table 1 summarizes the results of the simulations for the remaining parameters. The higher the average earnings of the poor in a state, the lower will be the equilibrium benefit. Conversely, the higher the average earnings of the poor in the rival state, the higher will be the equilibrium benefit. These comparative statics conform to the emerging pattern: Any characteristic which makes a state more attractive raises the caseload price and thus lowers the equilibrium benefit. Characteristics which make the rival more attractive lower the caseload price, raising the equilibrium benefit.

The effect of the state's unemployment rate on the equilibrium benefit level is ambiguous. This indeterminacy arises because $T_{i}$ exerts two opposing pressures on the AFDC caseload price. First, a lower unemployment rate will attract the poor, raising the caseload price and lowering $b_{i}$. Second, a lower $T_{i}$ will reduce the likelihood that a resident will join the AFDC rolls, reducing the caseload price and raising $b_{i}$.

The effect of the variable costs of migration and distance are similarly indeterminant. The greater the cost per mile of migration and the greater the distance to the rival, the less likely are a state's residents to out-migrate. Thus, 
Table 1. Comparative statics of migration equilibrium

\begin{tabular}{|c|c|c|c|c|}
\hline \multirow{2}{*}{ State income, $\mathbf{I}_{\mathrm{i}, \mathrm{j}}$} & $\partial b_{i}$ & \multirow{2}{*}{$>0$} & $\partial \mathrm{b}_{\mathrm{i}}$ & \multirow{2}{*}{$>0$} \\
\hline & $\partial \mathrm{I}_{\mathrm{i}}$ & & $\partial \mathrm{I}_{\mathrm{j}}$ & \\
\hline \multirow{2}{*}{ Poor population, $\mathrm{P}_{\mathrm{i}, \mathrm{j}}$} & $\partial b_{i}$ & \multirow{2}{*}{$<0$} & $\partial \mathrm{b}_{\mathrm{i}}$ & \multirow{2}{*}{$<0$} \\
\hline & $\partial \mathrm{P}_{\mathrm{i}}$ & & $\partial \mathrm{P}_{\mathrm{j}}$ & \\
\hline \multirow{3}{*}{$\begin{array}{l}\text { Cobb-Douglas preference } \\
\text { for other expenditure, } \\
\gamma_{\mathrm{i}, \mathrm{j}}\end{array}$} & $\partial b_{i}$ & \multirow{2}{*}{$<0$} & $\partial b_{i}$ & \multirow{3}{*}{$<0$} \\
\hline & $\partial \gamma_{i}$ & & $\partial \gamma_{j}$ & \\
\hline & $\partial \mathrm{b}_{\mathrm{i}}$ & \multirow{2}{*}{$<0$} & $\partial \mathrm{b}_{\mathrm{i}}$ & \\
\hline \multirow{2}{*}{ Average earnings, $E_{i, j}$} & $\partial \mathrm{E}_{\mathrm{i}}$ & & $\partial \mathrm{E}_{\mathbf{j}}$ & $>0$ \\
\hline & $\partial \mathrm{b}_{\mathrm{i}}$ & \multirow{2}{*}{$<0$} & $\partial \mathrm{b}_{\mathrm{j}}$ & \multirow{2}{*}{$<0$} \\
\hline $\begin{array}{l}\text { Probability of unemployment, } \\
T_{i, j}\end{array}$ & $\partial \mathrm{T}_{\mathrm{i}}$ & & $\partial \mathrm{T}_{\mathrm{j}}$ & \\
\hline $\begin{array}{l}\text { Federal matching share } \\
\left(1-s_{i, j}\right)\end{array}$ & $\frac{\sigma_{i}}{\partial\left(1-s_{i}\right)}$ & $>0$ & $\frac{\partial \mathrm{v}_{\mathrm{i}}}{\partial\left(1-\mathrm{s}_{\mathrm{j}}\right)}$ & $>0$ \\
\hline $\begin{array}{l}\text { Cost of migration, } \\
\text { per mile, } c\end{array}$ & $\frac{\partial \mathrm{b}_{i}}{\partial \mathrm{c}}$ & $<0$ & & \\
\hline Distance to rival, $\mathrm{d}_{\mathrm{ij}}$ & $\frac{\partial \mathrm{b}_{\mathrm{i}}}{\partial \mathrm{d}_{\mathrm{ij}}}$ & $<0$ & & \\
\hline
\end{tabular}

the higher are $c$ and $d$, the greater the caseload price of the benefit level. However, the higher are $c$ and $d$, the less likely are the rival's poor to inmigrate, lowering the caseload price. A priori, there is no reason to expect one effect to dominate the other.

Finally, the greater the Cobb-Douglas utility weight on other consumption $\left(\gamma_{\mathrm{i}}\right)$, the lower the state's equilibrium benefit level: States which prefer other consumption to the provision of some minimum income level for the poor offer lower AFDC benefit levels. The model also implies that the higher is the rival's utility weight on other consumption, the lower is the state's own benefit level, otherwise more of the rival's poor will be attracted.

The simulated comparative statics appear quite robust. First, the equilibrium benefits $\left(b_{i}{ }^{*}, b_{j}{ }^{*}\right)$ vary by only a few cents when the starting value varies from $\$ 0$ to $\$ 1000$. Second, the indicated direction of change in $b_{i}^{*}$ for a change in a given parameter does not vary when different exogenous values are used (except for $\mathrm{T}, \mathrm{c}$, and $\mathrm{d}_{\mathrm{ij}}$, as expected). The exact values selected were chosen so as to generate in-migration, out-migration, and no-migration equilibria. Furthermore, equilibria in which the budget set is convex and nonconvex resulted. In summary, the simulated comparative statics hold regardless of the exogenous values used, the direction of migration, or the shape of the budget constraint. 


\section{Empirical tests}

The two-state game theoretic model provides numerous testable implications. The major econometric challenge is to construct tests of these implications using forty-eight state data. One way is to structure the data so that each observation consists of a state's AFDC benefit level, its migration parameters, the migration parameters of another state (the rival), and the distance between the two states. For example, the average benefit level, unemployment rate, average earnings of the poor, et cetera, for Virginia would be paired with those variables (except the benefit level) for Maryland, along with the distance between Virginia and Maryland. Constructed in this fashion, each observation captures the benefit competition between two states. ${ }^{5}$

The question now is, which pairs of states ought to be considered as rivals? One can easily imagine contiguous states engaged in a benefit-setting game, so a data set composed of pairs of contiguous states seems appropriate. The poor do, however, migrate between nonbordering states, indicating that the contiguity criterion may be too restrictive. As the model itself does not imply a specific definition of rivalrous pairs, we examine various data sets. The base data set consists of all possible state pairs. We create other data sets by subsetting the base by distance between the states.

The model implies that a complex nonlinear relationship exists between the AFDC benefit level and the independent variables. Furthermore, a closed-form solution for the "global" best response apparently can not be analytically derived: There is no structural equation to which nonlinear estimation techniques can be applied. However, the "global" best response function can be characterized as an implicit function. This implicit function would be locally continuous and differentiable so it can be linearly approximated (locally) using a first order Taylor Series expansion. We estimate the following simple linear benefit function:

$$
\begin{aligned}
b_{i}= & a_{0}+a_{1}\left(1-T_{i}\right)+a_{2} \text { EARN }_{i}+a_{3} \gamma_{i}+a_{4} I_{i}+a_{5}\left(1-s_{i}\right)+ \\
& a_{6} P_{i}+a_{7}\left(1-T_{j}\right)+a_{8} E_{1} N_{j}+a_{9} \gamma_{j}+a_{10} I_{j}+a_{11}\left(1-s_{j}\right) \\
& +a_{12} P_{j}+a_{13} \text { DIST }+\epsilon_{i} .
\end{aligned}
$$

The random error $\left(\epsilon_{\mathrm{i}}\right)$ is assumed to be normally distributed. ${ }^{6}$

We can measure EARN by a variety of statistics. In 1979 females headed the majority of AFDC families, suggesting that the earnings of poor femaleheaded households $\left(\mathrm{FE}_{\mathrm{i}, \mathrm{j}}\right)$ would be appropriate. Nearly twenty percent of AFDC recipient families were headed by males however. Male earnings may also influence the migration decision so we also estimate the model using the average earnings of all poor families $\left(E_{i, j}\right)$. Also, AFDC recipients may respond to differences in the actual purchasing power of earnings rather than 
to nominal earnings. We use a state consumer price index to convert both nominal earnings measures, $\mathrm{E}$ and $\mathrm{FE}$, into real terms, RE and RFE respectively. ${ }^{7}$

We omit three variables in the theoretical model from (17). The cost of migration per mile (c) is omitted as it does not vary significantly over the sample, it simply scales distance. Next, the maximum values of the psychic cost distributions $\left(\mathrm{K}_{\mathrm{i}}\right.$ and $\left.\mathrm{K}_{\mathrm{j}}\right)$ are assumed to be constant and equal over all states. We make this assumption because estimation of psychic costs for even one group of potential migrants is beyond the scope of this study. ${ }^{8}$

The model is, of course, sensitive to the assumed form of the utility function. If one assumes that each state maximizes a Cobb-Douglas utility function without error, then each state will set the share of its total expenditures allocated to non-AFDC items $\left(\gamma_{i}\right)$ as follows:

$$
\gamma_{\mathrm{i}}=\frac{\mathrm{I}_{\mathrm{i}}-\mathrm{b}_{\mathrm{i}} \mathrm{s}_{\mathrm{i}} \mathrm{T}_{\mathrm{i}}\left(\mathrm{P}_{\mathrm{i}}+\mathrm{G}_{\mathrm{i}}\left(\mathrm{b}_{\mathrm{i}} ; \mathrm{b}_{\mathrm{j}}\right)\right)}{\mathrm{I}_{\mathrm{i}}} .
$$

Since the current $\gamma_{\mathrm{i}}$ is related to the current benefit level we use a lagged value of this expenditure share as an instrument. If states optimize with error or if state preferences are not consistent with the Cobb-Douglas specification, the non-AFDC expenditure share will measure $\gamma_{i}$ with error. As a consequence, least squares estimation will produce biased and inconsistent estimates.

In light of the potential errors in variables problem, one might consider making the assumption that preferences do not vary across states. The preference parameters $\gamma_{i}$ and $\gamma_{j}$ would then be constants, not regressors. If preferences are constant, least squares estimation of (17) excluding $\gamma_{i}$ and $\gamma_{j}$ will produce unbiased, consistent estimates. However, if preferences vary across states this specification omits relevant variables. OLS estimates will be biased and inconsistent (unless $\gamma_{\mathrm{i}}$ and $\gamma_{\mathrm{j}}$ are perfectly orthogonal to the other regressors). Because it is impossible to determine a priori which assumption is more realistic we run regressions based on each. The results do not differ significantly, so we report only the regressions which include the preference parameters.

The final specification issue concerns the state's share, $s_{\mathrm{i}}$. The federal matching schedules for AFDC cause the state share and the benefit level to be simultaneously related (see Moffitt, 1984). To control for this simultaneity we formulate the model as a system of three equations:

$$
\begin{gathered}
\mathrm{b}_{\mathrm{i}}=\mathrm{a}_{0}+\mathrm{a}_{1}\left(1-\mathrm{T}_{\mathrm{j}}\right)+\mathrm{a}_{2} \text { EARN }_{\mathrm{i}}+\mathrm{a}_{3} \gamma_{\mathrm{i}}+\mathrm{a}_{4} \mathrm{I}_{\mathrm{i}}+\mathrm{a}_{5}\left(1-\mathrm{s}_{\mathrm{i}}\right)+\mathrm{a}_{6} \mathrm{P}_{\mathrm{i}} \\
+\mathrm{a}_{7}\left(1-\mathrm{T}_{\mathrm{j}}\right)+\mathrm{a}_{8} \text { EARN }_{\mathrm{j}}+\mathrm{a}_{10} \mathrm{I}_{\mathrm{j}}+\mathrm{a}_{11}\left(1-\mathrm{s}_{\mathrm{j}}\right)+\mathrm{a}_{12} \mathrm{P}_{\mathrm{j}}+ \\
\mathrm{a}_{13} \text { DIST }+\epsilon_{\mathrm{i} 1} \\
\left(1-\mathrm{s}_{\mathrm{i}}\right)=\beta_{0}+\beta_{1} \text { TOTPOP }_{\mathrm{i}}+\beta_{2} \mathrm{I}_{\mathrm{i}}+\beta_{3} \mathrm{~b}_{\mathrm{i}}+\epsilon_{\mathrm{i} 2} \\
\left(1-\mathrm{s}_{\mathrm{j}}\right)=\delta_{0}+\delta_{1} \text { TOTPOP }_{\mathrm{j}}+\delta_{2} \mathrm{I}_{\mathrm{j}}+\delta_{3} \mathrm{~b}_{\mathrm{j}}+\epsilon_{\mathrm{j} 3}
\end{gathered}
$$


Table 2. 2SLS using all state pairs

\begin{tabular}{|c|c|c|c|c|c|}
\hline Eq. & Var & & & arameter estimate & \\
\hline bi & $\begin{array}{l}\operatorname{INT} \\
\left(1-T_{i}\right) \\
E_{i} \\
F_{i} \\
R_{i} \\
R_{i} E_{i} \\
P_{i} \\
\gamma_{i} \\
I_{i} \\
R_{i} \\
\left(1-s_{i}\right) \\
\left(1-T_{j}\right) \\
E_{j} \\
F_{j} \\
R_{j} \\
R_{j} \\
P_{j} \\
\gamma_{j} \\
I_{j} \\
R_{j} \\
\left(1-s_{j}\right) \\
D I_{j}\end{array}$ & $\begin{array}{l}(+/-) \\
(-) \\
(-) \\
(-) \\
(-) \\
(-) \\
(-) \\
(+) \\
(+) \\
(+) \\
(+) \\
(+) \\
(+) \\
(+) \\
(+) \\
(-) \\
(-) \\
(+) \\
(+) \\
(+) \\
(+)\end{array}$ & $\begin{array}{l}0.00003^{*} \\
-68.53 \\
-0.0026 \\
-152.38 \\
0.0702^{* *} \\
\bar{R}^{2}=.5509^{* *}\end{array}$ & $\begin{array}{c}0.0004 \\
0.000004 \\
-34.29 \\
-0.0007 \\
1.33 \\
0.0129^{* *} \\
\overline{\mathrm{R}}^{2}=.6877^{* *}\end{array}$ & $\begin{aligned} & 0.0015 \\
& 6.28 \mathrm{E}-07 \\
&- 12.86 \\
&- 0.0002 \\
& 1.13 \\
& 0.0025 \\
& \bar{R}^{2}=.8012^{* *}\end{aligned}$ \\
\hline$\left(1-s_{i}\right)$ & $\begin{array}{l}\text { INT } \\
\text { TOTPOP }_{\mathrm{i}} \\
\mathbf{I}_{\mathrm{i}} \\
\mathrm{RI}_{\mathrm{i}} \\
\mathrm{b}_{\mathrm{i}} \\
\mathrm{Rb}_{\mathrm{i}}\end{array}$ & $\begin{array}{l}(+) \\
(-) \\
(-) \\
(-) \\
(-)\end{array}$ & $\begin{array}{l}0.8194^{* *} \\
-2.51 \mathrm{E}-08^{* *} \\
0.00002^{* *} \\
-0.0002^{* *} \\
\overline{\mathbf{R}}^{2}=.4676^{* *}\end{array}$ & $\begin{array}{c}0.8446^{* *} \\
-3.15 \mathrm{E}-08^{* *} \\
0.00008^{* *} \\
-0.0006^{* *} \\
\overline{\mathrm{R}}^{2}=5028^{* *}\end{array}$ & $\begin{array}{c}0.8172^{* *} \\
-2.82 \mathrm{E}-08^{* *} \\
0.00007^{* *} \\
-0.0005^{* *} \\
\overline{\mathrm{R}}^{2}=.4826^{* *}\end{array}$ \\
\hline$\left(1-s_{j}\right)$ & $\begin{array}{l}\text { INT } \\
\text { TOTPOP }_{j} \\
\mathbf{I}_{\mathbf{j}} \\
\mathbf{R I}_{\mathbf{j}} \\
\mathrm{b}_{\mathbf{j}} \\
\mathbf{R b}_{\mathrm{j}}\end{array}$ & $\begin{array}{l}(+) \\
(-) \\
(-) \\
(-) \\
(-)\end{array}$ & $\begin{array}{c}0.8194^{* *} \\
-2.51 \mathrm{E}-08^{* *} \\
0.00002^{* *} \\
-0.0002^{* *} \\
\overline{\mathrm{R}}^{2}=.4676^{* *}\end{array}$ & $\begin{array}{c}0.8446^{* *} \\
-3.15 \mathrm{E}-08^{* *} \\
0.0008^{* *}\end{array}$ & $\begin{array}{c}0.8172^{* *} \\
-2.82 \mathrm{E}-08^{* *} \\
0.00007^{* *} \\
-0.0005^{* *} \\
\bar{R}^{2}=.4826^{* *}\end{array}$ \\
\hline
\end{tabular}

* Significant at $90 \%$ level.

** Significant at $95 \%$ level. 
Table 3. 2SLS using contiguous state pairs

\begin{tabular}{|c|c|c|c|c|c|c|}
\hline Eq. & Varia & ble & & Parameter & estimates & \\
\hline bi & 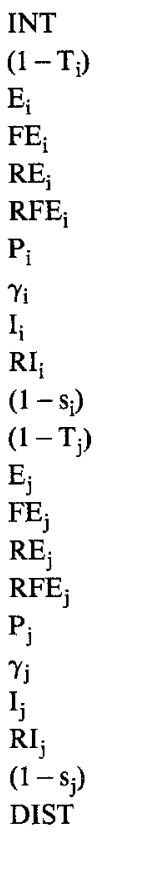 & $\begin{array}{l}(+/-) \\
(-) \\
(-) \\
(-) \\
(-) \\
(-) \\
(-) \\
(+) \\
(+) \\
(+) \\
(+/-) \\
(+) \\
(+) \\
(+) \\
(+) \\
(-) \\
(-) \\
(+) \\
(+) \\
(+) \\
(+/-)\end{array}$ & $\begin{array}{c}-0.0003^{* *} \\
-2443.17^{* *} \\
0.0087 \\
927.33 \\
0.2780^{* *} \\
\overline{\mathrm{R}}^{2}=.4386^{* *}\end{array}$ & $\begin{array}{c}-0.0001^{* *} \\
-691.78 \\
0.0078 \\
\\
547.91 \\
0.0872 \\
\bar{R}^{2}=.7293^{* *}\end{array}$ & $\begin{array}{l}-0.0411 \\
-0.00005^{* *} \\
-519.78 \\
\\
0.0014 \\
53.01 \\
0.0417 \\
\bar{R}^{2}=.5837^{* *}\end{array}$ & $\begin{array}{l}-0.0327 \\
-0.00001 \\
-220.19 \\
0.0028 \\
23.30 \\
-0.0205 \\
\bar{R}^{2}=.7408^{* *}\end{array}$ \\
\hline$\left(1-s_{i}\right)$ & $\begin{array}{l}\text { INT } \\
\text { TOTPOP }_{\mathrm{i}} \\
\mathrm{I}_{\mathrm{i}} \\
\mathrm{RI}_{\mathrm{i}} \\
\mathrm{b}_{\mathrm{i}} \\
\mathrm{Rb}_{\mathrm{i}}\end{array}$ & $\begin{array}{l}(+) \\
(-) \\
(-) \\
(-) \\
(-)\end{array}$ & $\begin{array}{c}0.8320^{* *} \\
-2.57 \mathrm{E}-08^{* *} \\
0.00002^{* *} \\
-0.0002^{* *} \\
\bar{R}^{2}=.4726^{* *}\end{array}$ & $\begin{array}{c}0.7986^{* *} \\
-2.14 \mathrm{E}-08^{* *} \\
0.00002^{* *} \\
-0.0002^{* *} \\
\overline{\mathrm{R}}^{2}=.4537^{* *}\end{array}$ & $\begin{array}{c}0.8500^{* *} \\
-3.09 \mathrm{E}-08^{* *} \\
0.00008^{* *}\end{array}$ & $\begin{array}{c}0.8260^{* *} \\
-2.81 \mathrm{E}-08^{* *} \\
0.00007^{* *} \\
-0.0005^{* *} \\
\overline{\mathrm{R}}^{2}=.4779\end{array}$ \\
\hline$\left(1-s_{j}\right)$ & $\begin{array}{l}\text { INT } \\
\text { TOTPOP }_{j} \\
\mathrm{I}_{\mathrm{j}} \\
\mathrm{RI}_{\mathrm{j}} \\
\mathrm{b}_{\mathrm{j}} \\
\mathrm{Rb}_{\mathrm{j}}\end{array}$ & $\begin{array}{l}(+) \\
(-) \\
(-) \\
(-) \\
(-)\end{array}$ & $\begin{array}{l}0.8279^{* *} \\
-2.52 \mathrm{E}-08^{* *} \\
0.00002^{* *}\end{array}$ & $\begin{array}{c}0.7967^{* *} \\
-2.12 \mathrm{E}-08 \\
0.0002^{* *}\end{array}$ & $\begin{array}{c}0.8465^{* *} \\
-3.05 \mathrm{E}-08^{* *} \\
0.00007^{* *}\end{array}$ & $\begin{array}{c}0.8240^{* *} \\
-2.78 \mathrm{E}-08^{* *} \\
0.00007^{* *}\end{array}$ \\
\hline
\end{tabular}

* Significant at $90 \%$ level.

** Significant at $95 \%$ level. 
where TOTPOP ${ }_{i}$ is the total population of state i. ${ }^{9}$

Equation (19) will be just identified if $\beta_{1}$ and $\delta_{1}$ are significantly different from zero. Equations (20) and (21) will be overidentified under a variety of restrictions; e.g., $\alpha_{11}$ and $\delta_{2}$ not equal to zero. ${ }^{10}$ Table 2 presents the Two State Least Squares (2SLS) estimates of the system using the all possible state pairs data set.

All three regressions explain a significant proportion of the variation in $b_{i}$. Most of the coefficients on the state's own characteristics are statistically significant and of the predicted sign. In particular, the federal share is positive and significant as predicted. The rival's characteristics are not significant. This result obtains due to the large distances between states in this data set. Distance is positive and significant in two of the regressions, suggesting that states are more concerned with in-migration than the ability to export the poor.

Next we estimate this same system using only contiguous state pairs (Table 3). All four regressions explain significant proportions of the variation in benefits. All of the state's own characteristics are statistically significant and of the expected sign in the benefit equation. The number of poor in the rival state $\left(\mathrm{P}_{\mathrm{j}}\right)$ exerts a significant negative impact in three of the regressions and the rival's utility weight on non-AFDC expenditure is significantly negative in one. The rival's characteristics do seem to matter (i.e., states play the benefit-setting game) when we consider contiguous states as rivals.

Estimation of the system using states pairs within 750 miles of each other indicates that at this distance the rival's characteristics are somewhat significant factors in a state's benefit choice (Table 4). ${ }^{11}$ In all regressions the state's own characteristics are all statistically significant and of the predicted sign. When we use the earnings of all poor families, nominal or real, to measure average earnings, the size of the rival's poor population is also significant and negative, as predicted. There is also evidence, though weaker, that the rival's taste for non-AFDC goods influences the state's benefit choice. When we use real earnings of poor female-headed households, none of the rival's characteristics appear significant.

\section{Summary and conclusions}

This paper estimated and tested a noncooperative game model of AFDC benefit determination. The model explicitly accounts for both the impact of benefit differentials on migration and the impact of migration on a state's choice of benefit levels. The empirical analysis generally supports the model's many implications. First, the greater the distance between the states, the less likely there is to be interdependent behavior. The regressions suggest that a rival state more 
Table 4. 2SLS using state pairs within 750 miles

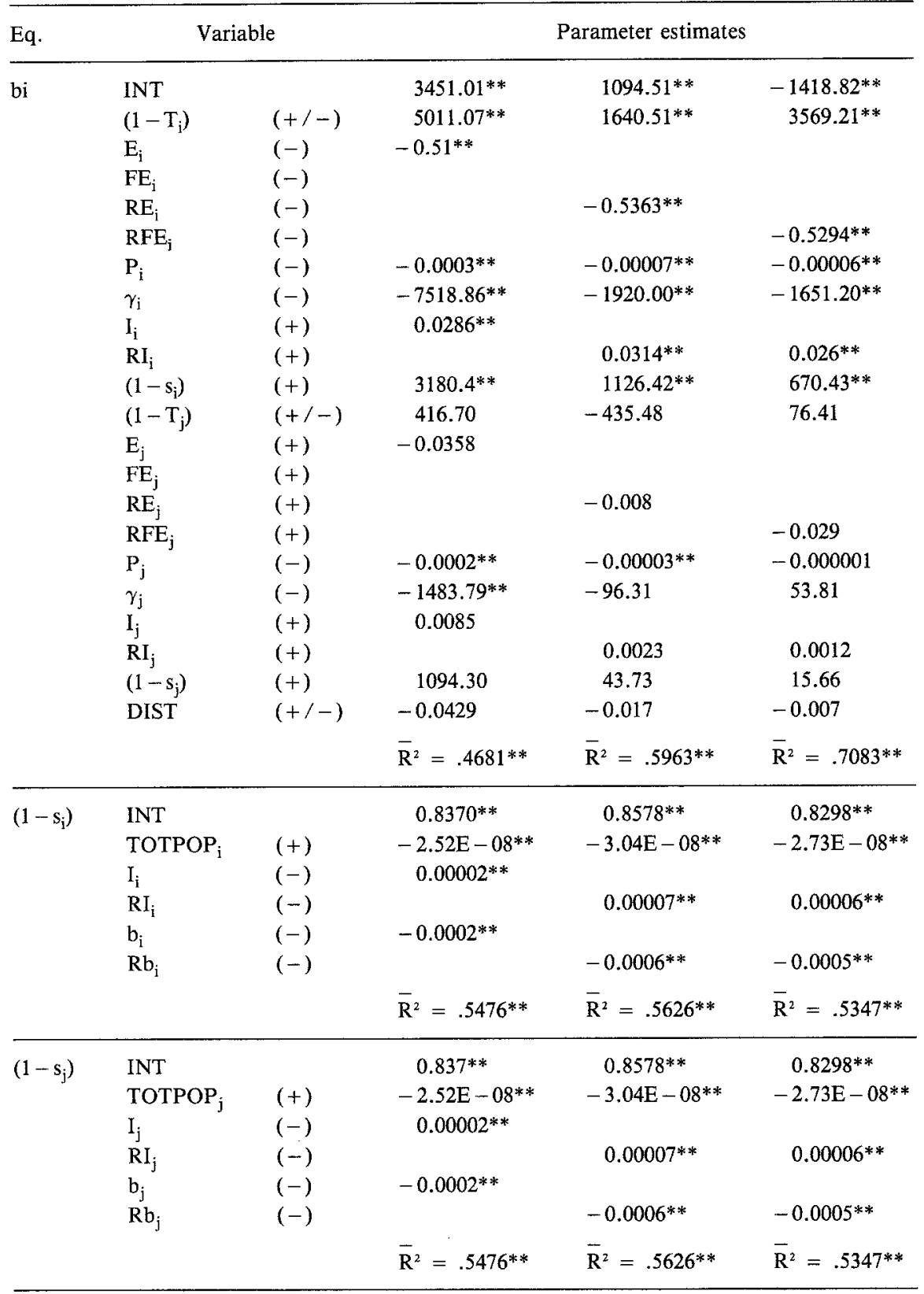

* Significant at $90 \%$ level.

** Significant at $95 \%$ level. 
than 750 miles away does not exert significant influence on a state's benefit decision.

Benefit levels of states within 750 miles are consistent with competitive benefit-setting behavior. Most notably, the larger the number of poor in the rival state, the lower the state's benefit level. The rival state's income and taste for non-AFDC goods exhibit positive and negative impacts respectively. These results obtain when we measure potential earnings as either nominal or real earnings of all poor families or as nominal earnings of poor female-headed households. When we measure potential earnings as real earnings of poor female-headed households, the significance of rival state characteristics dissipates.

While the methodological approach employed here differs from that of previous analyses, the results are consistent with earlier findings that AFDC recipients tend to migrate from lower to higher benefit states. Such recipient migration could impede the efficient spatial allocation of labor.

The results also indicate that states will offer lower benefits, on average, given recipient mobility than they would otherwise. That is, as long as recipients are mobile, state jurisdiction over benefit levels will lead to underprovision of AFDC. Migrating recipients constitute a spillover between states, thus optimal provision of AFDC requires federal jurisdiction.

\section{Notes}

1. Gramlich (1982) is a notable exception.

2. Distance is measured as miles between the states' largest SMSAs. If a state has two SMSAs, neither one being twice as large as the other, the average of the distances from both is used.

3. Debreu (1982) shows that if: (a) for every player the set of potential strategies is non-empty, compact, and convex; (b) if the pay-off function is continuous on the space of jointly potential strategies and quasi-concave in own strategy; and (c) if the correspondence defining the set of feasible strategies is continuous and convex-valued then the game has an equilibrium.

4. A copy of the program is available upon request.

5. The regressions were also run using a composite rival. This rival was constructed as a weighted average of the information from all other states. The weights were inversely related to distance. The results were similar, with the exception of increased collinearity.

6. A description of the data and sources is available from the author upon request.

7. The state consumer price index was constructed by Steven G. Craig and Robert P. Inman and used in their 1985 NBER paper.

8. For an example of such estimation see Deaton, Morgan, and Anschel (1982).

9. According to the matching formula, the federal share $\left(1-s_{i}\right)$ is a decreasing function of state income and an increasing function of state population.

10. For the model omitting $\gamma_{i}$ and $\gamma_{j}$, the order conditions are met and all three equations are overidentified given similar restrictions.

11. In regressions using states within 1000 miles and within 2000 miles of each other none of the rival's characteristics prove significant. 


\section{References}

Blank, R.M. (1988). The impact of state economic differentials on household welfare and labor force behavior. Journal of Urban Economics 24: 186-211.

Craig, S. and Inman, R. (1985). Education, welfare, and the 'new' federalism: State budgeting in a federalist economy. Working Paper \#1562 NBER.

Deaton, B., Morgan, L. and Anschel, K. (1982). The influence of psychic costs on rural-urban migration. American Journal of Agricultural Economics 64 (2): 177-187.

Debreu, G. (1982). Existence of competitive equilibrium. In K. Arrow and M. Intriligator (Eds.), Handbook of mathematical economics, 697-709. Amsterdam: North Holland.

Gramlich, E.M. (1982). An econometric examination of the new federalism. Brookings Papers on Economic Activity 2: 327-360.

Gramlich, E. and Laren, D. (1984). Migration and income redistribution responsibilities. Journal of Human Resources 19 (4): 489-511.

Moffitt, R. (1983). The effects of grants-in-aid on state and local expenditures: The case of AFDC. Journal of Public Economics 23: 279-306.

Orr, L. (1976). Income transfers as a public good: An application to AFDC. American Economic Review 66 (3): 359-371.

Pogue, T. and Sgontz, L. (1968). The effect of grants-in-aid on state-local spending. National Tax Journal 21 (2): 190-199.

Sjaastad, L. (1962). The costs and returns of human migration. Journal of Political Economy 70 (Supplement 5): 80-93.

Smith, P.K. (1988). Recipient migration and an AFDC benefit-setting game. Working Paper \#54. Department of Social Science. University of Michigan-Dearborn. 